REVIEW

\title{
Onset of effects of testosterone treatment and time span until maximum effects are achieved
}

\author{
Farid Saad ${ }^{1,2}$, Antonio Aversa ${ }^{3}$, Andrea M Isidori ${ }^{3}$ Livia Zafalon $^{4}$, Michael Zitzmann ${ }^{5}$ and Louis Gooren ${ }^{6}$ \\ ${ }^{1}$ Scientific Affairs Men's Healthcare, BU General Medicine/Men's Healthcare, Bayer Pharma AG, D-13342 Berlin, Germany, ${ }^{2}$ Gulf Medical University \\ School of Medicine, Ajman, United Arab Emirates, ${ }^{3}$ Medical Pathophysiology and Endocrinology Section, Department of Experimental Medicine, Sapienza \\ Università di Roma, Rome, Italy, ${ }^{4}$ Men's Healthcare, Bayer Pharma, São Paulo, Brazil, ${ }^{5}$ Center of Reproductive Medicine and Andrology, University of \\ Münster, Münster, Germany and ${ }^{6}$ Department of Endocrinology, VU Medical Center, Amsterdam, The Netherlands \\ (Correspondence should be addressed to F Saad; Email: farid.saad@bayer.com)
}

\begin{abstract}
Objective: Testosterone has a spectrum of effects on the male organism. This review attempts to determine, from published studies, the time-course of the effects induced by testosterone replacement therapy from their first manifestation until maximum effects are attained.

Design: Literature data on testosterone replacement.

Results: Effects on sexual interest appear after 3 weeks plateauing at 6 weeks, with no further increments expected beyond. Changes in erections/ejaculations may require up to 6 months. Effects on quality of life manifest within 3-4 weeks, but maximum benefits take longer. Effects on depressive mood become detectable after 3-6 weeks with a maximum after 18-30 weeks. Effects on erythropoiesis are evident at 3 months, peaking at 9-12 months. Prostate-specific antigen and volume rise, marginally, plateauing at 12 months; further increase should be related to aging rather than therapy. Effects on lipids appear after 4 weeks, maximal after 6-12 months. Insulin sensitivity may improve within few days, but effects on glycemic control become evident only after 3-12 months. Changes in fat mass, lean body mass, and muscle strength occur within 12-16 weeks, stabilize at 6-12 months, but can marginally continue over years. Effects on inflammation occur within 3-12 weeks. Effects on bone are detectable already after 6 months while continuing at least for 3 years.

Conclusion: The time-course of the spectrum of effects of testosterone shows considerable variation, probably related to pharmacodynamics of the testosterone preparation. Genomic and non-genomic effects, androgen receptor polymorphism and intracellular steroid metabolism further contribute to such diversity.
\end{abstract}

European Journal of Endocrinology 165 675-685

\section{Introduction}

Treatment of hypogonadal men with testosterone is rewarding, for the patients as well as the physician. The patient experiences, to his satisfaction, profound changes in his physical appearance and his mental makeup. The attending physician observes the changes the patient undergoes and rarely fails to be fascinated by the multitude of functions testosterone appears to have in the process of masculinization in the broadest sense (1).

While the effects of testosterone have been described in detail, relatively little attention has been given to the time these effects take to occur and achieve a full expression. This seems relevant. To the attending physician, monitoring the effects of administration of testosterone will be facilitated when it is known when certain effects can and should be expected. Patients like to receive information when the effects will set in. If patients have not been exposed to testosterone at the usual time of puberty, they must be prepared and counseled about the emergence of sexual thoughts and dreams, an increase in erections and seminal emissions, and when to expect them. Furthermore, this information is relevant for the design of clinical trials on testosterone replacement therapy. It is important to have information when an effect can be expected and when its maximum has been attained.

\section{Methodological search}

Data to compile a time-course for the diverse actions of testosterone are not easily available. They originate from studies analyzing the effects of testosterone administration to hypogonadal men or, alternatively, from studies on androgen deprivation. The main source of information will be the former category. Nearly all of these studies were not specifically designed to address 
the onset or time-dependency of effects of testosterone, nevertheless a number of controlled studies with different design and scheduled follow-up, allow a reasonable estimation.

Studies were identified by a computerized search of MEDLINE, the Cochrane Library, EMBASE, and Current Contents for the past 35 years (1976-2011), by searching the bibliographies of all retrieved articles and examining references of review articles found during the search to identify additional studies. The search was focused on trials published later than 1975, because at that time testosterone assays became widespread and more reliable. The computerized database search used the following keywords and MESH terms in any combination of: 'fat mass', 'lean mass/muscle/strength', 'body composition', 'bone density/markers', 'serum lipids/cholesterol', 'diabetes', 'glycemia', 'insulin resistance', 'inflammatory markers', 'endothelial function', 'sexual function', 'impotence/erectile/dysfunction', 'libido', 'mood', 'depression', 'cognitive function', 'polycythemia', 'prostate-specific antigen (PSA)', 'prostate cancer/hypertrophy/benign prostatic hyperplasia (BPH)' 'clinical trial', 'randomized clinical trial', with any combination of 'testosterone', 'testosterone therapy', 'steroid hormone replacement', or 'androgen therapy'. The search was limited to trials performed with testosterone, including testosterone esters and dihydrotestosterone preparations, independently of delivery. Inclusion criteria for eligible studies were: i) the use of one active treatment group compared with a matched placebo or control group, ii) the description of the time-course of the effect of active treatment, and iii) randomization, adherence to protocol, and single/double blinding. Only articles published in peer-reviewed medical journals were used; no abstracts were used.

There is now evidence that the spectrum of complaints of testosterone deficiency cannot be related to a specific threshold of testosterone concentrations, but that thresholds vary with the various symptoms of testosterone deficiency (2). In a cohort of men, androgen-related loss of libido or vigor became more prevalent when testosterone concentrations fell below $15 \mathrm{nmol} / \mathrm{l}$, while depression and diabetes mellitus type 2 (also in non-obese men) were significantly more present in men with testosterone concentrations below $10 \mathrm{nmol} / \mathrm{l}$. Symptoms related to androgen deficiency in this study could be subdivided into three independent groups: psychosomatic complaints, metabolic disorders, and sexual health problems. Patients suffering from one of these three groups exhibit distinct features in terms of androgen levels, age, and body mass index. So, complaints are not only linked to androgen levels but age and body mass index carried weight as well in the manifestation of signs and symptoms of androgen deficiency (2). To further complicate the matter of the relationship between testosterone levels on the one hand and symptoms of testosterone deficiency on the other hand, there is the multifactorial impact on certain androgen-related functions (2). Erectile dysfunction may serve as an example of a composite dysfunctionality in which arterial endothelial function, neuronal integrity, testosterone concentrations, and psychological factors play pivotal roles $(3,4)$, almost precluding establishing a straightforward relationship between testosterone levels and erectile dysfunction. In a study only testosterone concentrations below $8 \mathrm{nmol} / \mathrm{l}$ contributed to the symptom of erectile dysfunction (2).

Given that the clinical manifestations of testosterone deficiency do not occur at a definitive threshold value of circulating testosterone, but vary with the target organ, associated symptoms and underlying conditions, it is even more complicated to establish a time-course since a reversal of these symptoms of deficiency is not only dependent on restoring serum testosterone to normal. In fact, at least two new variables are to be entered into the model: pharmacodynamics of the testosterone preparation and pharmacogenomics of the treated subject. Indeed, if replacement therapy fails to restore idiosyncratic 'adequate' androgen levels, it also will fail to 'reverse' its clinical manifestations. The issue is that defining 'adequate' replacement will necessarily have a certain range of serum testosterone values.

A possible solution to this will be to replace 'universal threshold' with 'percentage rise' in circulating testosterone achieved under replacement therapy. The latter varies inversely with the starting concentration of testosterone and predicts the magnitude and rapidity of response to treatment. Thus, the less hypogonadal the subject, the larger the increase in circulating testosterone values must be for the effect to be 'perceived' by the subject, and the longer the duration of treatment to achieve an instrumentally measurable difference in the desired outcome (5).

The time-course for the spectrum of effects of testosterone may vary considerably, as testosterone actions are exerted through a cascade of many different pathways. Most of the actions of testosterone take place via the androgen receptor as a transcription factor activated by testosterone. The bound androgen receptor acts as transcription regulatory element by binding to specific DNA response elements in target gene promoters, causing activation or repression of transcription and subsequently protein synthesis. Over the past two decades evidence of rapid responses to androgens, dependent or independent of the androgen receptor, occurring at the cellular and organ level has accumulated. Androgen's rapid time-course of action; its effects in the absence or inhibition of the cellular machinery necessary for transcription/translation; and in the absence of translocation to the nucleus suggest a method of androgen action not initially dependent on genomic mechanisms (6). Examples are actions of testosterone on the brain and on vascular tone (7). 
In addition to the time-course of actions of testosterone on androgen-dependent biological variables, Table 1 presents an indication of quantitative changes associated with testosterone administration.

\section{Time-course of effects on muscle mass/strength}

In a series of studies, Bhasin et al. (8) have demonstrated that upon testosterone administration, there is a positive correlation between blood testosterone concentrations and leg press strength, thigh, and quadriceps muscle volume, and, further, levels of hemoglobin and IGF1. In a later study, the same group of authors concluded that

Table 1 Observed mean range of changes in selected measurable outcomes of testosterone administration to hypogonadal men in reviewed studies.

\begin{tabular}{|c|c|c|}
\hline Outcome & Values (range) & References \\
\hline Muscle mass (kg) & 0.4 to 16.4 & $(11-14,17,18,20,24)$ \\
\hline Strength ( 1 repetition max) & & $(11-20)$ \\
\hline Leg press strength $(\mathrm{kg})$ & 11.6 to 76.5 & \\
\hline Composite strength (\%) & 14 to 35 & \\
\hline Isokinetic power torque (Nm) & 4.7 to 9.6 & \\
\hline Handgrip (kg) & 3.5 to 5.3 & \\
\hline Bone mineral density & & $(24,25,27-29,94)$ \\
\hline Femoral neck $\left(\mathrm{g} / \mathrm{cm}^{2}\right)$ & 0.01 to 0.03 & \\
\hline Lumbar spine & & \\
\hline $\mathrm{g} / \mathrm{cm}^{2}$ & 0.04 to 0.1 & \\
\hline$(\%)$ & 5 to 8.6 & \\
\hline Body composition & & $(17,20,33,35,37)$ \\
\hline Total mass $(\mathrm{kg})$ & -3.2 to 1.69 & \\
\hline Fat mass $(\mathrm{kg})$ & -0.4 to -5.7 & \\
\hline Effects on lipids (mmol/l) & & $(38-41,43-47,55)$ \\
\hline Total cholesterol & -0.4 to -0.23 & \\
\hline Triglycerides & -0.98 to 0.1 & \\
\hline HDL cholesterol & -0.05 to 0.692 & \\
\hline LDL cholesterol & -0.39 to -0.05 & \\
\hline Glycemic control & & $\begin{array}{l}(34,39,43,46,49-51 \\
\quad 53-55)\end{array}$ \\
\hline Glucose (mmol/l) & -0.22 to -6.5 & \\
\hline Insulin (mIU/l) & -0.5 to -14.0 & \\
\hline HOMA index & -0.72 to -4.2 & \\
\hline $\mathrm{HbA} 1 \mathrm{c}(\%)$ & -0.2 to -6.3 & \\
\hline Cardiovascular effects $(\mathrm{mmHg})$ & & $\begin{array}{l}(25,38,44,47,62,64 \\
\quad 69)\end{array}$ \\
\hline Systolic BP & -0.5 to -7 & \\
\hline Diastolic BP & -0.5 to -7 & \\
\hline Pulse pressure & -1.9 to -2.6 & \\
\hline Pulse wave velocity & 0.2 to -0.7 & \\
\hline Augmentation index & -1.2 to -4.3 & \\
\hline Flow mediated dilatation (\%) & 1.8 to 2.6 & \\
\hline Inflammatory markers (pg/dl) & & $(35,42,46,50,68,69)$ \\
\hline IL6 & -0.02 to 1.6 & \\
\hline IL1 $\beta$ & -0.2 & \\
\hline IL10 & -0.15 & \\
\hline hs-CRP & -0.43 to -1.1 & \\
\hline TNF- $\alpha(\mathrm{mg} / \mathrm{dl})$ & 6.1 to -3.1 & \\
\hline Effects on erythropoiesis & & $(17,38,43,89,90)$ \\
\hline Hematocrit (\%) & 1.0 to 6.5 & \\
\hline Hemoglobin (g/dl) & 0.5 to 3.5 & \\
\hline Effects on prostate & & $(43,46,47,91-93,95)$ \\
\hline PSA (ng/ml) & -0.2 to 0.8 & \\
\hline Prostate volume $\left(\mathrm{cm}^{3}\right)$ & 0 to 10.1 & \\
\hline
\end{tabular}

the anabolic response to testosterone can largely be predicted by the dose administered (9). If the dose administered is too low, no effects may be demonstrable (10). Recent studies of the effects of testosterone on muscle mass/strength are mostly short term. In a study that combined testosterone with $\mathrm{GH}$, total lean body mass increased, as did appendicular lean tissue. Composite maximum voluntary strength of upper and lower body muscles had increased after 16 weeks (11). A study investigating the effect of a 12-week long-acting testosterone administration on maximal exercise capacity and muscle strength found an increase in quadriceps isometric strength, maximal voluntary contraction, and isokinetic strength (peak torque) (12). Testosterone administration for 20 weeks was associated with dose-dependent increases in skeletal muscle mass, leg strength, and power (13). In a study of 180 days of treatment with a $1 \%$ testosterone gel preparation (50 or $100 \mathrm{mg} /$ day, contained in 5 or $10 \mathrm{~g}$ gel), mean muscle strength in the leg press exercise increased by 90 days and had not improved further at 180 days (14). A study similar in design found an increase in lean body mass and an improvement of lower limb muscle strength after 6 months (15). Another study using high doses of testosterone gel (starting dose $100 \mathrm{mg} /$ day with possible up-titration to $150 \mathrm{mg} /$ day) observed significant increases in leg press strength, chest press strength, and stair climbing power with a load within 6 months (16). A study administering testosterone enanthate, $200 \mathrm{mg} / 2$ weeks observed major effects to occur over the first 12 months of testosterone administration, thereafter minor increases could be observed (17). It can be concluded that the effects of testosterone on muscle strength are demonstrable after 12-20 weeks and that depending on the achieved testosterone levels, the maximum effects are attained after 6 or 12 months. The data are summarized in Fig. 1.

\section{Time-course of effects on bone mineral density}

The effects of testosterone on bone mineral density are in part mediated by estrogens, derived from testosterone via aromatization (18). Testosterone improves bone mineral density at the lumbar spine compared with placebo, but at the femoral neck improvements are less certain (19). Testosterone produces a consistent reduction in bone resorption markers (20). Effects on bone mineral density have been shown in studies of 6 months duration $(21,22), 8$ months duration (23), or 1 year duration (24). From studies analyzing the effects of testosterone administration over as long as 36 months $(25,26)$ an increase was observed over that time period and it did not become clear whether the maximum effects of testosterone improving bone mineral have been attained after 36 months. The data are summarized in Fig. 1. 


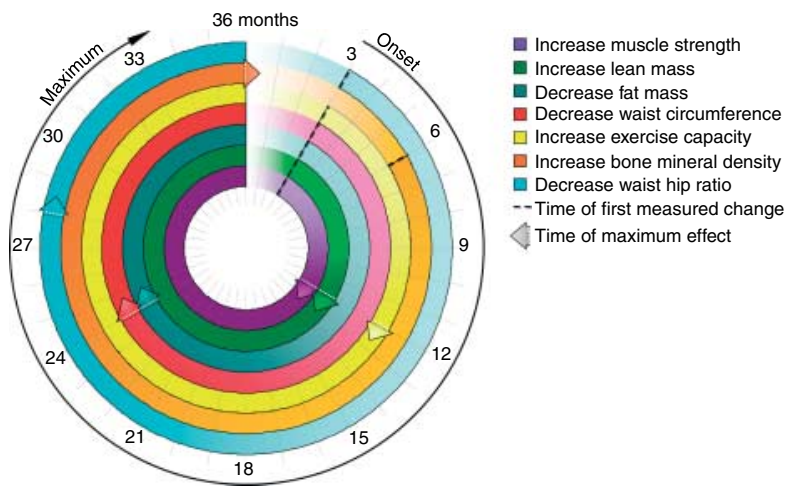

Figure 1 Time-course on body composition and strength.

\section{Time-course of effects on body composition}

Testosterone plays a significant role in obesity, glucose homeostasis, and lipid metabolism (27). At the cellular level there is now insight into the effects of androgen deprivation/administration on fat and muscle mass. Testosterone regulates lineage determination in mesenchymal pluripotent cells by promoting their commitment to the myogenic lineage and inhibiting their differentiation into the adipogenic lineage through an androgen receptor-mediated pathway. The observation that differentiation of pluripotent cells is androgen dependent provides a unifying explanation for the reciprocal effects of androgens on muscle and fat mass in men $(28,29)$. Upon testosterone administration there is a decrease in fat mass and an increase in lean body mass and the net result is often, but not always, that total body weight does not show major changes. An increase in total mass was found after 3 months (14) and an increase in weight in elderly men after 3 months (30). A decrease in weight has been observed after 3 months (31) and 6 months (17), with further progressive decrease over 24 months (32). An increase in total body mass, lean body mass, and a decrease in fat mass were found after 3 months $(14,30)$ or 6 months (17). A decrease in fat mass has been widely reported after 3 months $(14,30,31)$ or 6 months $(17)$, and a decrease in percent fat mass equally after 3 months $(14,31)$.

It is now commonly accepted that a preferential accumulation of fat in the abdominal region is associated with an increased risk of type 2 diabetes mellitus and cardiovascular disease, not only in obese subjects but even in non-obese subjects (33). Therefore, the effects on trunk fat, often measured as changes in waist circumference (34), are very relevant effects of testosterone treatment. A decrease in trunk fat or waist circumference was noted in a number of studies after 3 months $(35,36)$ with continuous decline over 24 months (32) and a decrease in the waist hip ratio after 3 months $(31,36)$ or after 6 months and 30 weeks respectively (17). A continued decline up to 110 weeks was reported (37). Body mass index as a widely used measure of body composition declined after 6 months with further improvement during an observation period of 2 years (32). The data are summarized in Fig. 1.

\section{Time-course of effects on lipids}

Decreases in serum total cholesterol have been noted as quick as after 4 weeks $(38,39)$ but most studies have reported a decrease after 3 months $(35,36)$. A decrease after 24 weeks was observed in a recent study (40), others have found this to occur after 9 months (41) or 12 months (42) with a maximum reached after 12 months (32).

The decrease in serum triglycerides follows a similar pattern: after 4 weeks (38), after 3 months (35), and with further decrease over 9 months (41) or 12 months (43).

The decrease in low-density lipoprotein cholesterol seems somewhat slower: after 3 months (35), after 40-44 weeks, (44) or after 12 months (42) with a maximum observed after 24 months (32).

Studies have found both an increase and decrease in high-density lipoprotein cholesterol. An increase was found to occur after 3 months increasing further during 12 months (43), after 6 months, (35) or close to 1 year (44). Continuous increase was observed over 24 months (32). The data are summarized in Fig. 2.

\section{Time-course of effects on glycemic control}

Several studies indicate that upon testosterone administration, serum glucose is reduced after 3 months in men with impaired glucose tolerance $(31,36,43)$. In a recent study, this was observed after 24 weeks only in men with baseline glucose $>110 \mathrm{ng} / \mathrm{ml}(6.6 \mathrm{mmol} / \mathrm{l})$

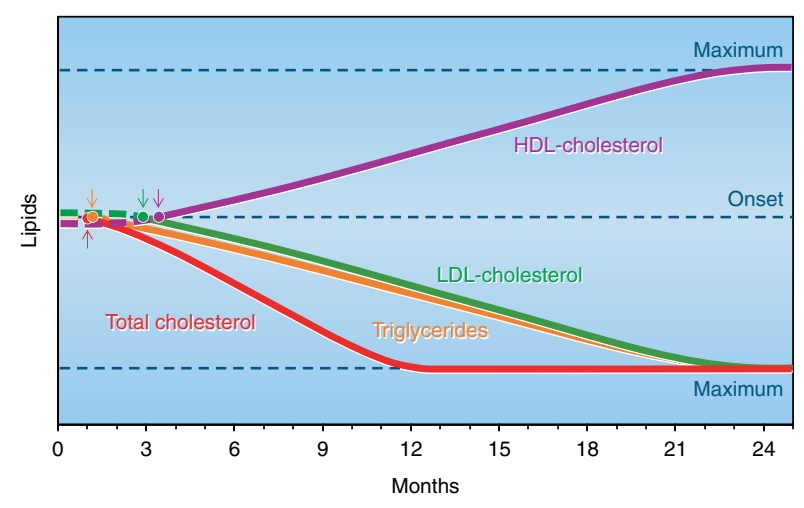

Figure 2 Time-course on lipids. 
but not significantly in men whose baseline glucose levels were $<110 \mathrm{ng} / \mathrm{ml}$ (6.6 mmol/l) (40). An early study reported a decrease in glucose and glucose disposal rate after 9 months (41).

A decrease in serum proinsulin and insulin was noted after 3 months (43) or 6 months (45), and a decrease in homeostasis model assessment index of insulin resistance (HOMA-IR) after 3 months (36) or 6 months (45-47).

A decline in HbA1c was observed after 3 months (31, $36,43)$ with further decrease after 12 months (43).

Low serum testosterone levels are associated with an adverse metabolic profile which may be explained by the observation that low testosterone levels and impaired mitochondrial function promote insulin resistance in men (48). And indeed, in an experimental study, stimulation of endogenous testosterone was shown to increase insulin sensitivity within $48 \mathrm{~h}$ (49).

Recently, it has been demonstrated that the interplay between insulin sensitivity, triglyceride levels, and androgens is practically immediate, as it occurs within a week, and is not facilitated by changes in body composition alone. Concomitantly increasing testosterone and decreasing estradiol $\left(\mathrm{E}_{2}\right)$ levels had positive effects on both postprandial triglyceride handling and insulin sensitivity in elaborate clamp models during manipulation of these serum sex steroid levels (50). The effects on postprandial triglyceride handling can therefore be observed in line with previous results and seem to be of relevance for metabolic risk $(51,52)$. An improvement in insulin sensitivity upon testosterone administration resulted in reduced fasting glucose and insulin levels within a single week (50), corroborating the former reports about an increase in insulin sensitivity upon stimulation of endogenous testosterone within $48 \mathrm{~h}$ (49) and an acute reduction in insulin sensitivity 2 weeks after discontinuing testosterone replacement in severely hypogonadal men (53).

Such observations are most likely attributed to testosterone-induced changes in lipid metabolism and/or altered postreceptor insulin signaling in muscle (54) and also improved insulin sensitivity enhancing muscle lipid uptake (55). Furthermore, the aforementioned intervention increased the response of postprandial glucose-dependent insulinotropic polypeptide (GIP) release (50). Effects of sex steroids on GIP had not been reported before. This is of specific interest, as action of GIP is not limited to pancreatic cells and may affect lipid homeostasis (56) and intestinal glucose transport (57). The data are summarized in Fig. 3.

\section{Time-course of effects on blood pressure and other cardiovascular effects}

In some studies a decline in diastolic blood pressure has been observed, after 3-9 months $(22,35,41,44)$ and in some studies in systolic blood pressure also $(35,44)$. Maximum effects were observed after 12 months (35).

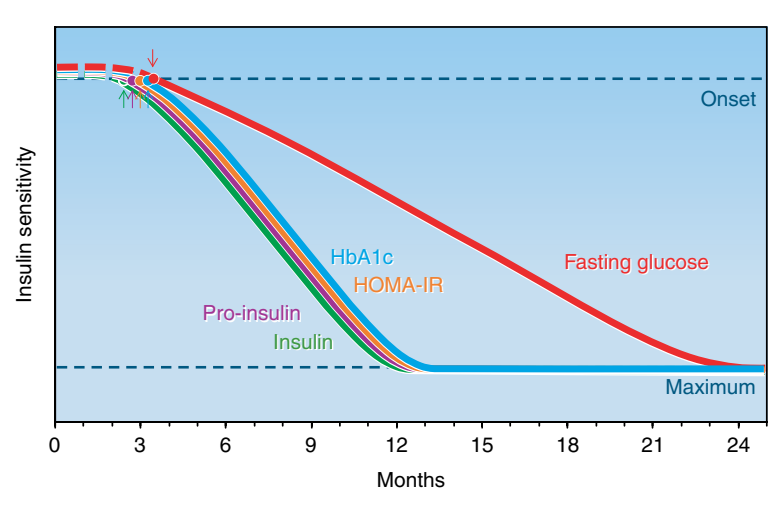

Figure 3 Time-course on glucose and insulin.

A decrease in the resting heart rate occurred after 40-44 weeks (44). A decrease in arterial stiffness measured as pulse wave velocity was measurable after $48 \mathrm{~h}$ (58) and in large artery compliance after 3 months (58). Several studies have been conducted in men with heart disease. In men with chronic stable angina pectoris the increase in time to $1 \mathrm{~mm}$ ST segment depression was noticeable after 14 weeks (59). The ischemic threshold had increased after 4 weeks (38). Exercise capacity in men with chronic heart failure increased after 12 weeks (60), whereas the cardiac index (cardiac output related to body surface) had already increased after $180 \mathrm{~min}$. In men with coronary artery disease flow-mediated vasodilatation was observed after 12 weeks (61).

\section{Time-course of effects on inflammatory factors/endothelial markers}

Low sex hormone levels are associated with inflammation (62). Already after 3 weeks of testosterone administration, a decline was noted in IL6 (63) and in another study after 16 weeks (64). A decrease in C-reactive protein (CRP) was observed after 3 weeks (63) and in other studies after 3 months $(32,43)$. In a study in patients with Crohn's disease, CRP levels continued to decline over 24 months (65). A decrease in tumor necrosis factor $\alpha$ and in interleukin $1 \beta$ was noted after 4 weeks (39). Asymmetric dimethylarginine is an endogenous NO synthase inhibitor and appears to decline upon testosterone administration after 10 days (66) or after 4 weeks (67).

\section{Time-course of effects on sexual parameters}

\section{Effects on libido}

Effects on libido, sexual desire, sexual thoughts and fantasies and satisfaction with sexual life manifest themselves rather rapidly: after 3 weeks (68) or 30 days (14). Some studies have measured these effects only after 3 months (31). 


\section{Effects on erection/ejaculation}

Effects on erection also appear rather rapidly: after 3 weeks (68). Increase in morning erections occur after 3 weeks (68). An increase in percentage of full erections and sexual performance and satisfaction with erections was noticed after 30 days $(14,69)$, an increase of ejaculations and sexual activity after 2 weeks (70) and 3 weeks respectively (68). In patients with veno-occlusive dysfunction, testosterone undecanoate restored erectile function after a minimum of 3 months and a maximum of 11.5 months (71).

The International Index of Erectile Function is a reliable, self-administered measure of erectile function that is cross-culturally valid and psychometrically sound, with the sensitivity and specificity for detecting treatment-related changes in patients with erectile dysfunction. It has five domains: erectile function, orgasmic function, sexual desire, intercourse satisfaction, and overall satisfaction. Increases in the IIEF erectile function have been noted after 3 months $(35,40)$ but increases in IIEF sexual desire, intercourse satisfaction, and overall satisfaction appear already after 6 weeks (40). Maximal effects are usually achieved after 3-6 months (72) but may take even up to 1 year in individual cases (71). The data are summarized in Fig. 4.

\section{Time-course of effects on quality of life}

The St Louis University Androgen Deficiency in Aging Male (ADAM) is a screening tool for hypogonadism in older males. An improvement was noted after 1 month of testosterone treatment (38). The Aging Males' Symptom (AMS) questionnaire is a 17-item scale assessing health-related quality of life and symptoms in aging men (e.g. somato-vegetative, psychological, and sexual symptoms) (73). Improvements on scores on the AMS have been noted after 1 month (38), 6 weeks (40)

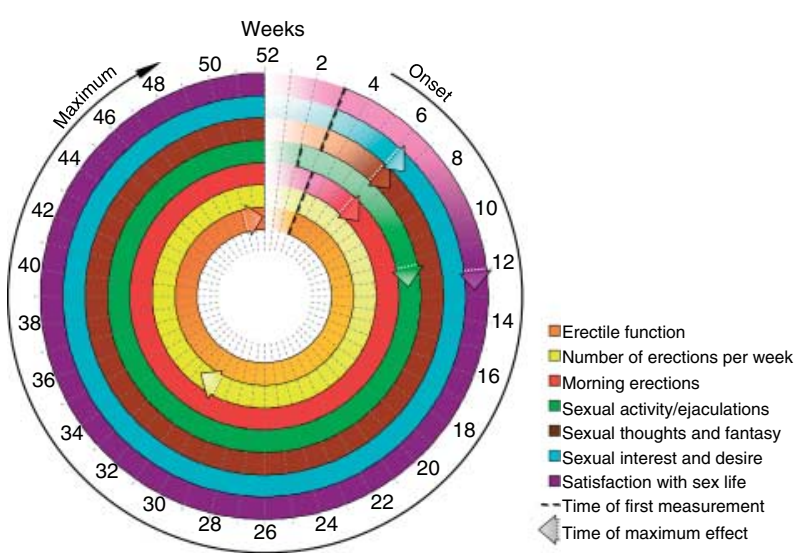

Figure 4 Time-course on sexual parameters. to 3 months on treatment with parenteral testosterone undecanoate (35) or after 9 months on testosterone gel (74) continuing over a total of 18 months (74).

\section{Time-course of effects on psychological variables}

Several studies report an improvement in depression after 3 weeks (68) or 1 month (38). Increase in good mood and a decrease in bad mood were noted after 3 weeks (68) or after 30 days (14). There was also an increase in motivation after 30 days which was maintained thereafter (14). Two studies using the Hamilton Depression Rating Scale found an improvement in depression after 6 weeks (75) or 8 weeks (76). A number of psychological variables (increase in sociability, decrease in anxiety, increase in concentration, and self-confidence) were apparent after 3 weeks (68). A decrease in fatigue and listlessness was found after 1 month (31) or 6 weeks (68). A transient increase in anger/hostility was found in eugonadal men whose testosterone levels were raised above normal after 2 weeks (77).

In a larger set of severely depressed men $(n=2 \times 50)$, effects of testosterone replacement therapy (TRT) by gel versus placebo were observed within 6 weeks. The effect was not consistent within the whole group of patients. It is likely that, in severe clinical depression, the receptiveness for testosterone effects depends on the overall pattern of disturbed neurotransmitters, especially noradrenaline and serotonin, and also baseline testosterone concentrations (78). It is very likely that the positive effects of testosterone on depressive symptoms start as early as after 3-6 weeks, but will most likely take 18-30 weeks to find the patient with a significant improvement. A recent study in hypogonadal men receiving i.m. testosterone undecanoate demonstrated such effects. It is remarkable that effects were more pronounced in men with the lowest baseline testosterone levels (79).

Similarly, effects of testosterone administration in hypogonadal men on the ability to process spatial data of visual content were observed within 2 weeks of treatment (80). These effects are obviously directly related to testosterone and not its aromatization product $\mathrm{E}_{2}$, as it was later confirmed in a placebocontrolled trial involving an aromatase inhibitor combined with testosterone administration in hypogonadal men. These patients exhibited a markedly improved spatial working memory within 3 weeks, improving further until week six (81).

\section{Time-course of effects on erythropoiesis}

The effects of testosterone on red blood cell formation (hemoglobin and hematocrit) are dose dependent 


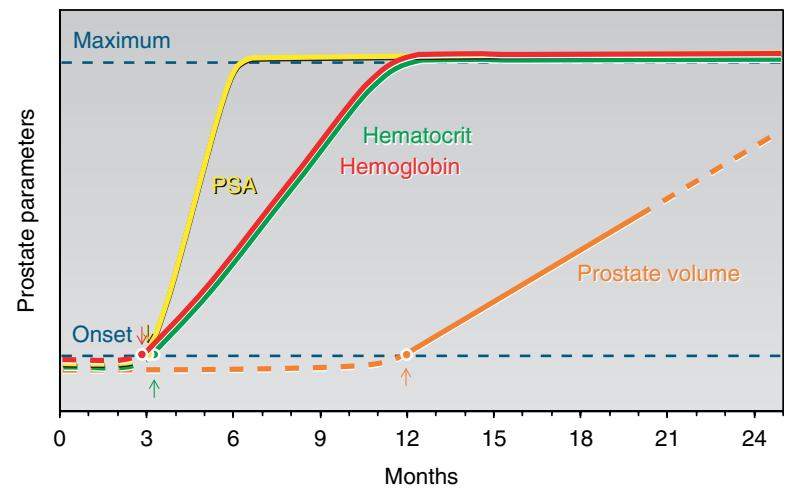

Figure 5 Time-course on hematocrit and prostate.

$(14,82,83)$ while higher age is also a factor (44). The effects are apparent after 3 months $(14,35,40)$ and a maximum is reached after 9-12 months (35). The data are summarized in Fig. 5.

\section{Time-course of effects on the prostate}

In hypogonadal men treated with testosterone, levels of PSA rise usually up to levels of eugonadal men (84). Upon judging the time-course of effects of testosterone on the prostate, it is of note that aging itself is a factor in the rise of both prostate volume and PSA (84), and there is no endpoint in the effects of testosterone on the prostate. A rise in PSA levels was noticed after 6 months, whereafter over the following 24 months there was no significant further increase (85). Other studies have found a rise of PSA levels after 3 months (40), some only after 12 months (43). An increase in prostate volume was noted after 3 months (86) and after 12 months (44). One study over 24 months found no significant increase in both PSA and prostate volume. In a study of 123 subjects over 42 months of testosterone gel application, there was significant increase in serum PSA over the first 6 months and then no further significant increases with continued testosterone treatment was found (87). In a study of 81 hypogonadal men (mean age 56.8 years) followed for a mean (range) of 33.8 (6-144) months PSA levels did not increase significantly at 1-year intervals for 5 years (88). The data are summarized in Fig. 5.

\section{Discussion}

This is a systematic analysis of the time-course of the spectrum of biological effects of testosterone on the various target systems. The authors view this as a worthwhile endeavor for a number of reasons. Attending physicians can prepare their patients for the intervening time periods before effects of testosterone can be experienced. Studies investigating the effects of testosterone have to take this time-course into consideration to design the duration of studies to be able to have quantifiable measurements.

It is of note that almost none of the quoted studies had been specifically designed to assess the time-course of effects. Some studies measure effects of testosterone only after 3 months (31), and, particularly, effects on libido and erections have occurred well before this time span (14, 68).

We noticed considerable differences in the occurrence of effects of testosterone. Effects on libido and other psychological variables and effects on vasculature occur rather rapidly. It may well be that these effects are not mediated via the classical androgen receptor but through other mechanisms like effects on membranes $(6,7)$. Also effects on erection occur rather rapidly and may be partially explained by non-genomic effects on vascular penile erectile tissue (89).

The effects of testosterone on glycemic control and variables clustered in the metabolic syndrome occur somewhat slower, but there is evidence that acute testosterone fall during deprivation therapy is directly related to a worsening in insulin sensitivity (53). However, in a recent study, the authors were not able to substantiate their earlier finding (90) and hypothesize insulin resistance associated with chronic low testosterone levels may be largely driven by decreased fat-free mass, increased percent body fat, and/or other metabolic regulatory factors. This may also apply to other factors of the metabolic syndrome. Testosterone inhibits the expression of the activity of lipoprotein lipase, the main enzymatic regulator of triglyceride uptake in the fat cell, preferentially in abdominal fat $(28,29)$. Several studies have indeed confirmed that testosterone treatment reduces waist circumference which, in its simplicity, appears to be a valid parameter of the degree of visceral obesity (91). In our own studies, signs and symptoms of the metabolic syndrome improved substantially following administration of long-acting testosterone undecanoate (32, $35,92)$ and improvements in glycemic control and lipids parallel improvements in body composition.

The effects of testosterone on muscle and bone involve protein synthesis and are a result of genomic actions of testosterone and, therefore, rather slow.

Apart from reviewing the onset of effects of testosterone treatment in hypogonadal men, it would also be possible to look at the onset of symptoms of testosterone deficiency in patients on androgen deprivation therapy (ADT), standard treatment for men with advanced prostate cancer. ADT causes unfavorable changes in body composition, insulin resistance and other risk factors for cardiometabolic diseases leading to an increased incidence of cardiovascular diseases and type 2 diabetes (for review $(93,94)$ ). However, deprivation of testosterone and the time-dependent 
effects thereof might be totally different from the onset of testosterone action in testosterone treatment, even in the same parameter. Therefore, it was decided to restrict this paper to aspects of testosterone treatment.

Finally, in the present analysis it was attempted to select those studies of testosterone treatment that provided adequate doses/delivery of testosterone. It is obvious that sub-optimal therapeutic regimens or, alternatively, inappropriate patient selection (eugonadal or men with biochemical but not clinical hypogonadism) may show different time-course of effects.

In conclusion, this analysis tries to chart the differences in time periods after which biological effects of testosterone administration in hypogonadal men occur. This may add to a better understanding of the physiology of androgen action. Earlier studies have shown that there are thresholds for the various actions testosterone: in other words signs and symptoms of testosterone deficiency appear at different threshold values of circulating testosterone. The above results call for a well-designed study that charts the time required to restore an androgen-dependent function with the optimal circulating testosterone for that specific androgen-dependent function. These studies are not easy to perform. Ideally, they should measure at what serum levels of testosterone, all androgen-dependent biological functions are restored. Some biological functions, like erectile functions are composite in nature, and next to testosterone, endothelial function and psychological factors are equally relevant (2). A major problem is the so-called late onset hypogonadism: the decline in serum testosterone with aging. It is still hotly debated whether this is a true form of hypogonadism, or a decline of serum testosterone associated with the progressive accumulation of health problems with aging $(95,96)$, but rather independently of the process of aging itself. Though small-scale studies show benefits and acceptable risks of treating elderly men with lower than normal testosterone levels $(46,97)$, a verdict can only be reached with large-scale studies including 5000 men over 5 years (95), for which presently the funding is not available. There is a degree of consensus that elderly men with serum testosterone clearly below the reference ranges and persistent clear clinical signs of hypogonadism may justifiably be treated $(98,99)$, but there remains a large degree of dissent.

\section{Declaration of interest}

The authors declare that there is no conflict of interest that could be perceived as prejudicing the impartiality of the research reported.

\section{Funding}

No financial or other support was received for the preparation of this manuscript. F Saad and L Zafalon are employees of Bayer Pharma. A Aversa received grants from Bayer Pharma and Lilly, Inc. L Gooren received compensation for lecturing from Bayer Pharma.

\section{Acknowledgements}

Ines Gerhardt is thanked for creation of the figures.

\section{References}

1 Nieschlag E. Testosterone treatment comes of age: new options for hypogonadal men. Clinical Endocrinology $2006 \quad 65 \quad 275-281$. (doi:10.1111/j.1365-2265.2006.02618.x)

2 Zitzmann M, Faber S \& Nieschlag E. Association of specific symptoms and metabolic risks with serum testosterone in older men. Journal of Clinical Endocrinology and Metabolism 200691 4335-4343. (doi:10.1210/jc.2006-0401)

3 Bancroft J. The endocrinology of sexual arousal. Journal of Endocrinology 2005186 411-427. (doi:10.1677/joe.1.06233)

4 Aversa A, Isidori AM, Spera G, Lenzi A \& Fabbri A. Androgens improve cavernous vasodilation and response to sildenafil in patients with erectile dysfunction. Clinical Endocrinology $2003 \mathbf{5 8}$ 632-638. (doi:10.1046/j.1365-2265.2003.01764.x)

5 Isidori AM, Greco EA \& Aversa A. Androgen deficiency and hormone-replacement therapy. BJU International $200596212-$ 216. (doi:10.1111/j.1464-410X.2005.05603.x)

6 Foradori CD, Weiser MJ \& Handa RJ. Non-genomic actions of androgens. Frontiers in Neuroendocrinology 200829 169-181. (doi:10.1016/j.yfrne.2007.10.005)

7 Malkin CJ, Jones RD, Jones TH \& Channer KS. Effect of testosterone on $e x$ vivo vascular reactivity in man. Clinical Science 2006111 265-274. (doi:10.1042/CS20050354)

8 Bhasin S, Woodhouse L, Casaburi R, Singh AB, Bhasin D, Berman N, Chen X, Yarasheski KE, Magliano L, Dzekov C, Dzekov J, Bross R, Phillips J, Sinha-Hikim I, Shen R \& Storer TW. Testosterone dose-response relationships in healthy young men. American Journal of Physiology. Endocrinology and Metabolism 2001 281 E1172-E1181.

9 Woodhouse LJ, Reisz-Porszasz S, Javanbakht M, Storer TW, Lee M, Zerounian H \& Bhasin S. Development of models to predict anabolic response to testosterone administration in healthy young men. American Journal of Physiology. Endocrinology and Metabolism 2003284 E1009-E1017. (doi:10.1152/ajpendo.00536.2002)

10 Snyder PJ, Peachey H, Hannoush P, Berlin JA, Loh L, Lenrow DA, Holmes JH, Dlewati A, Santanna J, Rosen CJ \& Strom BL. Effect of testosterone treatment on body composition and muscle strength in men over 65 years of age. Journal of Clinical Endocrinology and Metabolism 199984 2647-2653. (doi:10.1210/jc.84.8.2647)

11 Sattler FR, Castaneda-Sceppa C, Binder EF, Schroeder ET, Wang Y, Bhasin S, Kawakubo M, Stewart Y, Yarasheski KE, Ulloor J, Colletti P, Roubenoff R \& Azen SP. Testosterone and growth hormone improve body composition and muscle performance in older men. Journal of Clinical Endocrinology and Metabolism 2009 94 1991-2001. (doi:10.1210/jc.2008-2338)

12 Caminiti G, Volterrani M, Iellamo F, Marazzi G, Massaro R, Miceli M, Mammi C, Piepoli M, Fini M \& Rosano GM. Effect of longacting testosterone treatment on functional exercise capacity, skeletal muscle performance, insulin resistance, and baroreflex sensitivity in elderly patients with chronic heart failure a doubleblind, placebo-controlled, randomized study. Journal of the American College of Cardiology 200954 919-927. (doi:10.1016/ j.jacc.2009.04.078)

13 Storer TW, Woodhouse L, Magliano L, Singh AB, Dzekov C, Dzekov J \& Bhasin S. Changes in muscle mass, muscle strength, and power but not physical function are related to testosterone dose in healthy older men. Journal of the American Geriatrics Society 2008 56 1991-1999. (doi:10.1111/j.1532-5415.2008.01927.x)

14 Wang C, Swerdloff RS, Iranmanesh A, Dobs A, Snyder PJ, Cunningham G, Matsumoto AM, Weber T \& Berman N. Transdermal testosterone gel improves sexual function, mood, muscle strength, and body composition parameters in hypogonadal men. Journal of Clinical Endocrinology and Metabolism 200085 2839-2853. (doi:10.1210/jc.85.8.2839) 
15 Srinivas-Shankar U, Roberts SA, Connolly MJ, O'Connell MD, Adams JE, Oldham JA \& Wu FC. Effects of testosterone on muscle strength, physical function, body composition, and quality of life in intermediate-frail and frail elderly men: a randomized, doubleblind, placebo-controlled study. Journal of Clinical Endocrinology and Metabolism 2010 95 639-650. (doi:10.1210/jc.2009-1251)

16 Basaria S, Coviello AD, Travison TG, Storer TW, Farwell WR, Jette AM, Eder R, Tennstedt S, Ulloor J, Zhang A, Choong K, Lakshman KM, Mazer NA, Miciek R, Krasnoff J, Elmi A, Knapp PE, Brooks B, Appleman E, Aggarwal S, Bhasin G, Hede-Brierley L, Bhatia A, Collins L, LeBrasseur N, Fiore LD \& Bhasin S. Adverse events associated with testosterone administration. New England Journal of Medicine 2010363 109-122. (doi:10.1056/NEJMoa 1000485)

17 Page ST, Amory JK, Bowman FD, Anawalt BD, Matsumoto AM, Bremner WJ \& Tenover JL. Exogenous testosterone (T) alone or with finasteride increases physical performance, grip strength, and lean body mass in older men with low serum T. Journal of Clinical Endocrinology and Metabolism 200590 1502-1510. (doi:10. 1210/jc.2004-1933)

18 Ohlsson C \& Vandenput L. The role of estrogens for male bone health. European Journal of Endocrinology 2009160 883-889. (doi:10.1530/EJE-09-0118)

19 Tracz MJ, Sideras K, Bolona ER, Haddad RM, Kennedy CC, Uraga MV, Caples SM, Erwin PJ \& Montori VM. Testosterone use in men and its effects on bone health. A systematic review and metaanalysis of randomized placebo-controlled trials. Journal of Clinical Endocrinology and Metabolism 200691 2011-2016. (doi:10. 1210/jc.2006-0036)

20 Isidori AM, Giannetta E, Greco EA, Gianfrilli D, Bonifacio V, Isidori A, Lenzi A \& Fabbri A. Effects of testosterone on body composition, bone metabolism and serum lipid profile in middle-aged men: a meta-analysis. Clinical Endocrinology 2005 63 280-293. (doi:10.1111/j.1365-2265.2005.02339.x)

21 Emmelot-Vonk MH, Verhaar HJ, Nakhai Pour HR, Aleman A, Lock TM, Bosch JL, Grobbee DE \& van der Schouw YT. Effect of testosterone supplementation on functional mobility, cognition, and other parameters in older men: a randomized controlled trial. Journal of the American Medical Association 2008299 39-52. (doi:10.1001/jama.2007.51)

22 Anderson FH, Francis RM \& Faulkner K. Androgen supplementation in eugonadal men with osteoporosis-effects of 6 months of treatment on bone mineral density and cardiovascular risk factors. Bone $1996 \mathbf{1 8}$ 171-177. (doi:10.1016/8756-3282 (95)00441-6)

23 Zitzmann M, Brune $M$ \& Nieschlag E. Vascular reactivity in hypogonadal men is reduced by androgen substitution. Journal of Clinical Endocrinology and Metabolism $2002 \quad 87$ 5030-5037. (doi:10.1210/jc.2002-020504)

24 Basurto L, Zarate A, Gomez R, Vargas C, Saucedo R \& Galvan R. Effect of testosterone therapy on lumbar spine and hip mineral density in elderly men. Aging Male 200811 140-145. (doi:10. 1080/13685530802273715)

25 Snyder PJ, Peachey H, Hannoush P, Berlin JA, Loh L, Holmes JH, Dlewati A, Staley J, Santanna J, Kapoor SC, Attie MF, Haddad JG Jr \& Strom BL. Effect of testosterone treatment on bone mineral density in men over 65 years of age. Journal of Clinical Endocrinology and Metabolism 199984 1966-1972. (doi:10. 1210/jc.84.6.1966)

26 Amory JK, Watts NB, Easley KA, Sutton PR, Anawalt BD, Matsumoto AM, Bremner WJ \& Tenover JL. Exogenous testosterone or testosterone with finasteride increases bone mineral density in older men with low serum testosterone. Journal of Clinical Endocrinology and Metabolism 200489 503-510. (doi:10.1210/ jc.2003-031110)

27 Allan CA \& McLachlan RI. Androgens and obesity. Current Opinion in Endocrinology, Diabetes, and Obesity 201017 224-232. (doi:10. 1097/MED.0b013e3283398ee2)

28 Singh R, Artaza JN, Taylor WE, Gonzalez-Cadavid NF \& Bhasin S. Androgens stimulate myogenic differentiation and inhibit adipogenesis in $\mathrm{C} 3 \mathrm{H}$ 10T1/2 pluripotent cells through an androgen receptor-mediated pathway. Endocrinology $2003 \mathbf{1 4 4}$ 5081-5088. (doi:10.1210/en.2003-0741)

29 Singh R, Artaza JN, Taylor WE, Braga M, Yuan X, GonzalezCadavid NF \& Bhasin S. Testosterone inhibits adipogenic differentiation in 3T3-L1 cells: nuclear translocation of androgen receptor complex with beta-catenin and T-cell factor 4 may bypass canonical Wnt signaling to down-regulate adipogenic transcription factors. Endocrinology 2006 147 141-154. (doi:10.1210/en. 2004-1649)

30 Tenover JS. Effects of testosterone supplementation in the aging male. Journal of Clinical Endocrinology and Metabolism $1992 \mathbf{7 5}$ 1092-1098. (doi:10.1210/jc.75.4.1092)

31 Boyanov MA, Boneva Z \& Christov VG. Testosterone supplementation in men with type 2 diabetes, visceral obesity and partial androgen deficiency. Aging Male 20036 1-7.

32 Haider A, Gooren LJ, Padungtod P \& Saad F. Improvement of the metabolic syndrome and of non-alcoholic liver steatosis upon treatment of hypogonadal elderly men with parenteral testosterone undecanoate. Experimental and Clinical Endocrinology $\mathcal{E}$ Diabetes 2010118 167-171. (doi:10.1055/s-0029-1202774)

33 Zitzmann M. Testosterone deficiency, insulin resistance and the metabolic syndrome. Nature Reviews. Endocrinology 20095 673-681. (doi:10.1038/nrendo.2009.212)

34 Bosy-Westphal A, Booke CA, Blocker T, Kossel E, Goele K, Later W, Hitze B, Heller M, Gluer CC \& Muller MJ. Measurement site for waist circumference affects its accuracy as an index of visceral and abdominal subcutaneous fat in a Caucasian population. Journal of Nutrition 2010140 954-961. (doi:10.3945/jn.109.118737)

35 Saad F, Gooren L, Haider A \& Yassin A. An exploratory study of the effects of 12 month administration of the novel long-acting testosterone undecanoate on measures of sexual function and the metabolic syndrome. Archives of Andrology 200753 353-357. (doi:10.1080/01485010701730880)

36 Kapoor D, Goodwin E, Channer KS \& Jones TH. Testosterone replacement therapy improves insulin resistance, glycaemic control, visceral adiposity and hypercholesterolaemia in hypogonadal men with type 2 diabetes. European Journal of Endocrinology 2006154 899-906. (doi:10.1530/eje.1.02166)

37 Minnemann T, Schubert M, Freude S, Hubler D, Gouni-Berthold I, Schumann C, Christoph A, Oettel M, Ernst M, Mellinger U, Krone W \& Jockenhovel F. Comparison of a new long-acting testosterone undecanoate formulation vs testosterone enanthate for intramuscular androgen therapy in male hypogonadism. Journal of Endocrinological Investigation 200831 718-723.

38 Malkin CJ, Pugh PJ, Morris PD, Kerry KE, Jones RD, Jones TH \& Channer KS. Testosterone replacement in hypogonadal men with angina improves ischaemic threshold and quality of life. Heart 200490 871-876. (doi:10.1136/hrt.2003.021121)

39 Malkin CJ, Pugh PJ, Jones RD, Kapoor D, Channer KS \& Jones TH. The effect of testosterone replacement on endogenous inflammatory cytokines and lipid profiles in hypogonadal men. Journal of Clinical Endocrinology and Metabolism 200489 3313-3318. (doi:10.1210/jc.2003-031069)

40 Moon du G, Park MG, Lee SW, Park K, Park JK, Kim SW, Park NC, Ahn TY, Paick JS, Seo JT, Yang DY, Lee JY \& Kim JJ. The efficacy and safety of testosterone undecanoate $(\operatorname{Nebido}((\mathrm{R})))$ in testosterone deficiency syndrome in Korean: a multicenter prospective study. Journal of Sexual Medicine 2010 7 2253-2260. (doi:10. $1111 /$ j.1743-6109.2010.01765.x)

41 Marin P, Holmang S, Gustafsson C, Jonsson L, Kvist H, Elander A, Eldh J, Sjostrom L, Holm G \& Bjorntorp P. Androgen treatment of abdominally obese men. Obesity Research 19931 245-251.

42 Zgliczynski S, Ossowski M, Slowinska-Srzednicka J, Brzezinska A, Zgliczynski W, Soszynski P, Chotkowska E, Srzednicki M \& Sadowski Z. Effect of testosterone replacement therapy on lipids and lipoproteins in hypogonadal and elderly men. Atherosclerosis 1996121 35-43. (doi:10.1016/0021-9150(95)05673-4)

43 Heufelder AE, Saad F, Bunck MC \& Gooren L. Fifty-two-week treatment with diet and exercise plus transdermal testosterone reverses the metabolic syndrome and improves glycemic control in 
men with newly diagnosed type 2 diabetes and subnormal plasma testosterone. Journal of Andrology 200930 726-733. (doi:10. 2164/jandrol.108.007005)

44 Zitzmann M \& Nieschlag E. Androgen receptor gene CAG repeat length and body mass index modulate the safety of long-term intramuscular testosterone undecanoate therapy in hypogonadal men. Journal of Clinical Endocrinology and Metabolism 200792 3844-3853. (doi:10.1210/jc.2007-0620)

45 Pagotto U, Gambineri A, Pelusi C, Genghini S, Cacciari M, Otto B, Castaneda T, Tschop M \& Pasquali R. Testosterone replacement therapy restores normal ghrelin in hypogonadal men. Journal of Clinical Endocrinology and Metabolism $2003 \mathbf{8 8} 4139-4143$. (doi:10.1210/jc.2003-030554)

46 Aversa A, Bruzziches R, Francomano D, Rosano G, Isidori AM, Lenzi A \& Spera G. Effects of testosterone undecanoate on cardiovascular risk factors and atherosclerosis in middle-aged men with late-onset hypogonadism and metabolic syndrome: results from a 24-month, randomized, double-blind, placebocontrolled study. Journal of Sexual Medicine 20107 3495-3503. (doi:10.1111/j.1743-6109.2010.01931.x)

47 Naharci MI, Pinar M, Bolu E \& Olgun A. Effect of testosterone on insulin sensitivity in men with hypogonadotropic hypogonadism. Endocrine Practice 200716 629-635.

48 Pitteloud N, Mootha VK, Dwyer AA, Hardin M, Lee H, Eriksson KF, Tripathy D, Yialamas M, Groop L, Elahi D \& Hayes FJ. Relationship between testosterone levels, insulin sensitivity, and mitochondrial function in men. Diabetes Care 200528 1636-1642. (doi:10. 2337/diacare.28.7.1636)

49 Pitteloud N, Hardin M, Dwyer AA, Valassi E, Yialamas M, Elahi D \& Hayes FJ. Increasing insulin resistance is associated with a decrease in Leydig cell testosterone secretion in men. Journal of Clinical Endocrinology and Metabolism $2005902636-2641$. (doi:10.1210/jc.2004-2190)

50 Lapauw B, Ouwens M, t Hart LM, Wuyts B, Holst JJ, T'Sjoen G, Kaufman JM \& Ruige JB. Sex steroids affect triglyceride handling, glucose-dependent insulinotropic polypeptide, and insulin sensitivity: a 1-week randomized clinical trial in healthy young men. Diabetes Care 201033 1831-1833. (doi:10.2337/dc10-0515)

51 Agledahl I, Skjaerpe PA, Hansen JB \& Svartberg J. Low serum testosterone in men is inversely associated with non-fasting serum triglycerides: the Tromso study. Nutrition, Metabolism, and Cardiovascular Diseases $2008 \quad 18$ 256-262. (doi:10.1016/j. numecd.2007.01.014)

52 Ruige JB \& Van Gaal LF. Low fasting triglycerides: hallmark of the healthy large hip? Obesity 200917 1621-1626. (doi:10.1038/ oby.2009.25)

53 Yialamas MA, Dwyer AA, Hanley E, Lee H, Pitteloud N \& Hayes FJ. Acute sex steroid withdrawal reduces insulin sensitivity in healthy men with idiopathic hypogonadotropic hypogonadism. Journal of Clinical Endocrinology and Metabolism 200792 4254-4259. (doi:10.1210/jc.2007-0454)

54 Belfort R, Mandarino L, Kashyap S, Wirfel K, Pratipanawatr T, Berria R, Defronzo RA \& Cusi K. Dose-response effect of elevated plasma free fatty acid on insulin signaling. Diabetes $2005 \mathbf{5 4}$ 1640-1648. (doi:10.2337/diabetes.54.6.1640)

55 Ukropcova B, McNeil M, Sereda O, de Jonge L, Xie H, Bray GA \& Smith SR. Dynamic changes in fat oxidation in human primary myocytes mirror metabolic characteristics of the donor. Journal of Clinical Investigation 2005115 1934-1941. (doi:10.1172/ JCI24332)

56 Song DH, Getty-Kaushik L, Tseng E, Simon J, Corkey BE \& Wolfe MM. Glucose-dependent insulinotropic polypeptide enhances adipocyte development and glucose uptake in part through Akt activation. Gastroenterology 2007133 1796-1805. (doi:10.1053/j.gastro.2007.09.005)

57 Singh SK, Bartoo AC, Krishnan S, Boylan MO, Schwartz JH \& Michael Wolfe M. Glucose-dependent insulinotropic polypeptide (GIP) stimulates transepithelial glucose transport. Obesity 2008 16 2412-2416. (doi:10.1038/oby.2008.393)

58 Yaron M, Greenman Y, Rosenfeld JB, Izkhakov E, Limor R, Osher E, Shenkerman G, Tordjman K \& Stern N. Effect of testosterone replacement therapy on arterial stiffness in older hypogonadal men. European Journal of Endocrinology 2009160 839-846. (doi:10.1530/EJE-09-0052)

59 English KM, Steeds RP, Jones TH, Diver MJ \& Channer KS. Lowdose transdermal testosterone therapy improves angina threshold in men with chronic stable angina: a randomized, double-blind, placebo-controlled study. Circulation $2000 \quad 102 \quad 1906-1911$. (doi:10.1161/01.CIR.102.16.1906)

60 Pugh PJ, Jones RD, West JN, Jones TH \& Channer KS. Testosterone treatment for men with chronic heart failure. Heart 200490 446-447. (doi:10.1136/hrt.2003.014639)

61 Kang SM, Jang Y, Kim JY, Chung N, Cho SY, Chae JS \& Lee JH. Effect of oral administration of testosterone on brachial arterial vasoreactivity in men with coronary artery disease. American Journal of Cardiology 200289 862-864. (doi:10.1016/S00029149(02)02202-6)

62 Maggio M, Basaria S, Ble A, Lauretani F, Bandinelli S, Ceda GP, Valenti G, Ling SM \& Ferrucci L. Correlation between testosterone and the inflammatory marker soluble interleukin- 6 receptor in older men. Journal of Clinical Endocrinology and Metabolism 2006 91 345-347. (doi:10.1210/jc.2005-1097)

63 Guler N, Batyraliev T, Dulger H, Ozkara C, Tuncer M, Aslan S, Okut $\mathrm{H} \&$ Agirbasli $\mathrm{M}$. The effects of short term (3 weeks) testosterone treatment on serum inflammatory markers in men undergoing coronary artery stenting. International Journal of Cardiology 2006109 339-343. (doi:10.1016/j.ijcard.2005. 06.027)

64 Zitzmann M, Erren M, Kamischke A, Simoni M \& Nieschlag E. Endogenous progesterone and the exogenous progestin norethisterone enanthate are associated with a proinflammatory profile in healthy men. Journal of Clinical Endocrinology and Metabolism 2005 90 6603-6608. (doi:10.1210/jc.2005-0847)

65 Haider A, Kurtz W, Giltay EJ, Gooren LJ \& Saad F. Administration of testosterone to elderly hypogonadal men with Crohn's disease improves their Crohn's disease activity index: a pilot study. Hormone Molecular Biology and Clinical Investigation 20102 287-292. (doi:10.1515/HMBCI.2010.033)

66 Cakir E, Ozcan O, Yaman H, Akgul EO, Bilgi C, Erbil MK \& Yesilova Z. Elevated plasma concentration of asymmetric dimethylarginine that is reduced by single dose testosterone administration in idiopathic hypogonadotropic hypogonadism patients. Journal of Clinical Endocrinology and Metabolism 2005 90 1651-1654. (doi:10.1210/jc.2004-2045)

67 Leifke E, Kinzel M, Tsikas D, Gooren L, Frolich JC \& Brabant G. Effects of normalization of plasma testosterone levels in hypogonadal men on plasma levels and urinary excretion of asymmetric dimethylarginine (ADMA). Hormone and Metabolic Research 2008 40 56-59. (doi:10.1055/s-2007-1004529)

68 Jockenhovel F, Minnemann T, Schubert M, Freude S, Hubler D, Schumann C, Christoph A, Gooren L \& Ernst M. Timetable of effects of testosterone administration to hypogonadal men on variables of sex and mood. Aging Male 200912 113-118. (doi:10. 3109/13685530903322858)

69 Wang C \& Swerdloff RS. Should the nonaromatizable androgen dihydrotestosterone be considered as an alternative to testosterone in the treatment of the andropause? Journal of Clinical Endocrinology and Metabolism 200287 1462-1466. (doi:10.1210/jc. $87.4 .1462)$

70 Nieschlag E, Buchter D, Von Eckardstein S, Abshagen K, Simoni M \& Behre HM. Repeated intramuscular injections of testosterone undecanoate for substitution therapy in hypogonadal men. Clinical Endocrinology 199951 757-763. (doi:10.1046/j.13652265.1999.00881.x)

71 Yassin AA, Saad F \& Traish A. Testosterone undecanoate restores erectile function in a subset of patients with venous leakage: a series of case reports. Journal of Sexual Medicine 20063 727-735. (doi:10.1111/j.1743-6109.2006.00267.x)

72 Yassin AA \& Saad F. Improvement of sexual function in men with late-onset hypogonadism treated with testosterone only. Journal of Sexual Medicine 20074 497-501. (doi:10.1111/j.1743-6109. 2007.00442.x) 
73 Daig I, Heinemann LA, Kim S, Leungwattanakij S, Badia X, Myon E, Moore C, Saad F, Potthoff P \& Thai DM. The aging males' symptoms (AMS) scale: review of its methodological characteristics. Health and Quality of Life Outcomes 20031 77. (doi:10. 1186/1477-7525-1-77)

74 Saad F, Gooren L, Haider A \& Yassin A. Effects of testosterone gel followed by parenteral testosterone undecanoate on sexual dysfunction and on features of the metabolic syndrome. Andrologia 200840 44-48. (doi:10.1111/j.1439-0272.2008.00807.x)

75 Perry PJ, Yates WR, Williams RD, Andersen AE, MacIndoe JH, Lund BC \& Holman TL. Testosterone therapy in late-life major depression in males. Journal of Clinical Psychiatry 200263 1096-1101. (doi:10.4088/JCP.v63n1202)

76 Pope HG Jr, Cohane GH, Kanayama G, Siegel AJ \& Hudson JI. Testosterone gel supplementation for men with refractory depression: a randomized, placebo-controlled trial. American Journal of Psychiatry 2003160 105-111. (doi:10.1176/appi. ajp.160.1.105)

77 O'Connor DB, Archer J \& Wu FC. Effects of testosterone on mood, aggression, and sexual behavior in young men: a double-blind, placebo-controlled, cross-over study. Journal of Clinical Endocrinology and Metabolism 200489 2837-2845. (doi:10.1210/jc. 2003-031354)

78 Pope HG Jr, Amiaz R, Brennan BP, Orr G, Weiser M, Kelly JF, Kanayama G, Siegel A, Hudson JI \& Seidman SN. Parallel-group placebo-controlled trial of testosterone gel in men with major depressive disorder displaying an incomplete response to standard antidepressant treatment. Journal of Clinical Psychopharmacology 201030 126-134. (doi:10.1097/JCP.0b013e3181d207ca)

79 Giltay EJ, Tishova YA, Mskhalaya GJ, Gooren LJ, Saad F \& Kalinchenko SY. Effects of testosterone supplementation on depressive symptoms and sexual dysfunction in hypogonadal men with the metabolic syndrome. Journal of Sexual Medicine 2010 7 2572-2582. (doi:10.1111/j.1743-6109.2010.01859.x)

80 Zitzmann M, Weckesser M, Schober O \& Nieschlag E. Changes in cerebral glucose metabolism and visuospatial capability in hypogonadal males under testosterone substitution therapy. Experimental and Clinical Endocrinology \& Diabetes 2001109 302-304. (doi:10.1055/s-2001-16351)

81 Cherrier MM, Matsumoto AM, Amory JK, Ahmed S, Bremner W, Peskind ER, Raskind MA, Johnson M \& Craft S. The role of aromatization in testosterone supplementation: effects on cognition in older men. Neurology 200564 290-296. (doi:10.1212/ 01.WNL.0000149639.25136.CA)

82 Dobs AS, Meikle AW, Arver S, Sanders SW, Caramelli KE \& Mazer NA. Pharmacokinetics, efficacy, and safety of a permeationenhanced testosterone transdermal system in comparison with bi-weekly injections of testosterone enanthate for the treatment of hypogonadal men. Journal of Clinical Endocrinology and Metabolism 199984 3469-3478. (doi:10.1210/jc.84.10.3469)

83 Coviello AD, Kaplan B, Lakshman KM, Chen T, Singh AB \& Bhasin S. Effects of graded doses of testosterone on erythropoiesis in healthy young and older men. Journal of Clinical Endocrinology and Metabolism 200893 914-919. (doi:10.1210/jc.2007-1692)

84 Behre HM, Bohmeyer J \& Nieschlag E. Prostate volume in testosterone-treated and untreated hypogonadal men in comparison to age-matched normal controls. Clinical Endocrinology 1994 40 341-349. (doi:10.1111/j.1365-2265.1994.tb03929.x)

85 Snyder PJ, Peachey H, Berlin JA, Hannoush P, Haddad G, Dlewati A, Santanna J, Loh L, Lenrow DA, Holmes JH, Kapoor SC, Atkinson LE \& Strom BL. Effects of testosterone replacement in hypogonadal men. Journal of Clinical Endocrinology and Metabolism $2000 \mathbf{8 5}$ 2670-2677. (doi:10.1210/jc.85.8.2670)

86 Meikle AW, Arver S, Dobs AS, Adolfsson J, Sanders SW, Middleton RG, Stephenson RA, Hoover DR, Rajaram L \& Mazer NA. Prostate size in hypogonadal men treated with a nonscrotal permeation-enhanced testosterone transdermal system. Urology 199749 191-196. (doi:10.1016/S0090-4295 (96)00445-1)
87 Wang C, Cunningham G, Dobs A, Iranmanesh A, Matsumoto AM, Snyder PJ, Weber T, Berman N, Hull L \& Swerdloff RS. Long-term testosterone gel (AndroGel) treatment maintains beneficial effects on sexual function and mood, lean and fat mass, and bone mineral density in hypogonadal men. Journal of Clinical Endocrinology and Metabolism 200489 2085-2098. (doi:10.1210/jc.2003032006)

88 Coward RM, Simhan J \& Carson CC III. Prostate-specific antigen changes and prostate cancer in hypogonadal men treated with testosterone replacement therapy. BJU International 2009103 1179-1183. (doi:10.1111/j.1464-410X.2008.08240.x)

89 Waldkirch E, Uckert S, Schultheiss D, Geismar U, Bruns C, Scheller F, Jonas U, Becker AJ, Stief CG \& Hedlund P. Non-genomic effects of androgens on isolated human vascular and nonvascular penile erectile tissue. BJU International $2008 \mathbf{1 0 1} 71-75$; discussion 75. (doi:10.1111/j.1464-410X.2007.07182.x)

90 Rabiee A, Dwyer AA, Caronia LM, Hayes FJ, Yialamas MA, Andersen DK, Thomas B, Torriani M \& Elahi D. Impact of acute biochemical castration on insulin sensitivity in healthy adult men. Endocrine Research 201035 71-84. (doi:10.3109/07435 801003705601 )

91 Esmaillzadeh A, Mirmiran P \& Azizi F. Metabolic abnormalities identified by anthropometric measures in elderly men. American Journal of Clinical Nutrition 200683 173; author reply 173-174.

92 Saad F, Gooren LJ, Haider A \& Yassin A. A dose-response study of testosterone on sexual dysfunction and features of the metabolic syndrome using testosterone gel and parenteral testosterone undecanoate. Journal of Andrology 200829 102-105. (doi:10. 2164/jandrol.107.002774)

93 Saylor PJ \& Smith MR. Metabolic complications of androgen deprivation therapy for prostate cancer. Journal of Urology 2009 181 1998-2006; discussion 2007-1998. (doi:10.1016/j.juro. 2009.01.047)

94 Levine GN, D’Amico AV, Berger P, Clark PE, Eckel RH, Keating NL, Milani RV, Sagalowsky AI, Smith MR \& Zakai N. Androgendeprivation therapy in prostate cancer and cardiovascular risk: a science advisory from the American Heart Association. American Cancer Society, and American Urological Association: endorsed by the American Society for Radiation Oncology. CA: A Cancer Journal for Clinicians 201060 194-201. (doi:10.3322/caac.20061)

95 Cunningham GR \& Toma SM. Clinical review: why is androgen replacement in males controversial? Journal of Clinical Endocrinology and Metabolism 201196 38-52. (doi:10.1210/jc. 2010-0266)

96 McLachlan RI. Certainly more guidelines than rules. Journal of Clinical Endocrinology and Metabolism $2010 \quad 95$ 2610-2613. (doi:10.1210/jc.2010-0838)

97 Bassil N \& Morley JE. Late-life onset hypogonadism: a review. Clinics in Geriatric Medicine 201026 197-222. (doi:10.1016/j. cger.2010.02.003)

98 Wang C, Nieschlag E, Swerdloff R, Behre HM, Hellstrom WJ, Gooren LJ, Kaufman JM, Legros JJ, Lunenfeld B, Morales A, Morley JE, Schulman C, Thompson IM, Weidner W \& Wu FC. Investigation, treatment and monitoring of late-onset hypogonadism in males: ISA, ISSAM, EAU, EAA and ASA recommendations. European Journal of Endocrinology 2008159 507-514. (doi:10. 1530/EJE-08-0601)

99 Bhasin S, Cunningham GR, Hayes FJ, Matsumoto AM, Snyder PJ, Swerdloff RS \& Montori VM. Testosterone therapy in men with androgen deficiency syndromes: an Endocrine Society clinical practice guideline. Journal of Clinical Endocrinology and Metabolism 201095 2536-2559. (doi:10.1210/jc.2009-2354)

Received 23 February 2011

Revised version received 20 June 2011

Accepted 13 July 2011 